\title{
RESENHA
}

FONSECA, André Dioney; COSTA, Lorena Lopes da (Orgs.). Reflexões e existência: universidade pública e a formação de professores de história no interior da Amazônia. Uberlândia: Navegando Publicações, 2021, 198p. Disponível em:

https://www.editoranavegando.com/livro-reflexoes. Acesso em: 20 dez. $2021 .{ }^{1}$

\section{PENSAR E EXISTIR, EM TEMPOS DE RESISTIR}

\author{
Daniela Molina \\ Universidade de São Paulo, Faculdade de Educação, Brasil \\ dmolina@usp.br
}

Os outros lugares são espelhos em negativo. O viajante reconhece o pouco que é seu descobrindo o muito que não teve e o que não terá. (CALVINO, 2003, p. 15)

O grande historiador Michel de Certeau apontava que o exercício da escrita da História seria uma forma de se lidar com a alteridade, de um "outro" ausente, que nos escapou e se perdeu, de modo que em cada relato histórico se estabelece uma espécie de "jogo da vida com a morte" (CERTEAU, 2002, p. 57). Lacunas, apagamentos e esquecimentos certamente são questões que envolvem a prática historiadora, mas, talvez, no caso dos estudos históricos dedicados à região amazônica e às suas populações, essas ausências sejam ainda mais constantes, em função de uma tradição historiográfica comprometida com projetos políticos e sociais que, na maior parte do tempo, buscou construir uma história nacional identificada com as sociedades europeias, anulando o protagonismo dos sujeitos históricos regionais.

Diante disso, o livro "Reflexões e existência: universidade pública e a formação de professores de história no interior da Amazônia", organizado pelos professores André Dioney Fonseca e Lorena Lopes da Costa, e publicado eletronicamente pela Navegando Publicações em 2021, é um esforço coletivo na contramão dos apagamentos e silenciamentos, ao registrar as experiências, dificuldades e desafios enfrentados por docentes e estudantes do curso de História da Universidade Federal do Oeste do Pará (Ufopa).

Nesse livro, o leitor vai encontrar a produção de um olhar crítico de vários docentes sobre suas próprias práticas e as experiências de sala de aula, salas estas compostas por muitos

\footnotetext{
${ }^{1}$ A versão impressa encontra-se no prelo pela mesma editora.
} 
sujeitos historicamente invisibilizados: indígenas, quilombolas, afrodescendentes, ribeirinhos. Seus autores, todos professores do curso de Licenciatura em História da Ufopa, alguns originários da própria terra, outros para lá atraídos, elegem a sala de aula como o centro de suas reflexões para, a partir delas, reconfigurarem suas próprias práticas docentes e a própria relação com o conhecimento histórico. Os organizadores, também autores de dois dos textos, tiveram o cuidado de dividir a obra em três seções: uma dedicada às reflexões sobre a formação docente, outra voltada às experiências no ensino de História e a última orientada às reflexões teóricas na sala de aula, num movimento que parte de uma dimensão mais geral (as grandes questões políticas nacionais) para uma outra mais particular (as questões regionais e locais e o próprio pequeno universo da sala de aula), muito embora se possa observar que essas dimensões estejam em constante diálogo na obra como um todo. A distribuição dos textos ao longo das seções se dá de maneira desigual: a primeira é composta por três textos, a segunda, a mais extensa, por cinco e a terceira reúne apenas dois.

O primeiro texto da parte I da obra (Política e Formação Docente), intitula-se: “O ensino de história do Brasil republicano em um contexto de crise", de autoria de André Dioney Fonseca, também um dos organizadores da obra. Balizando sua reflexão sobre a própria prática docente na Ufopa a partir do recém percurso da história política brasileira e os processos espúrios que culminaram na ascensão da extrema direita no Brasil, o autor tece considerações de como esse quadro crítico do cenário político e social brasileiro o levou a reconsiderar seu papel enquanto docente de um curso de formação de professores de história no interior da Amazônia. Dentre tantos desafios que tal empreitada lhe impôs, o docente discorre sobre algumas de suas práticas na imperiosa desconstrução da imagem técnico-burocrática do professor, ainda presente na formação docente, para se pensar numa trajetória formativa que possa cada vez mais abrir espaço para a emergência do professor como um "intelectual reflexivo e transformador".

Em "Avaliação formativa: experiências na formação em história", segundo texto da seção, Douglas Mota Xavier de Lima, propõe uma reflexão sobre a efetividade dos processos avaliativos tradicionais na formação profissional dos alunos como professores. Norteando as discussões sobre os processos avaliativos no ensino superior e seu papel na formação do professor, a partir da contribuição de diversos autores que se dedicaram a essa questão, o autor traz um relato de suas experiências em torno das mudanças promovidas no processo avaliativo em sua disciplina do curso de História da Ufopa, a fim de superar práticas tradicionais e promover uma formação mais significativa aos futuros professores e uma vivência mais próxima dos estudantes de graduação com a realidade escolar. 
Que conexões a Ufopa, em seus 10 anos de existência estabeleceu com os povos indígenas da região amazônica? Essa é a indagação que orienta as reflexões das professoras Wania Alexandrino Viana e Elenise Pinto de Arruda, no terceiro e último texto (da primeira parte da obra) intitulado: "Políticas de ações afirmativas e os estudantes indígenas do Instituto de Ciências da Educação (Iced): vivências e desafios nos 10 anos da Universidade Federal do Oeste do Pará (Ufopa)". A discussão proposta pelas autoras se estabelece em torno de dois enfoques: o das políticas afirmativas encampadas pela instituição ao longo de seus 10 anos de existência e o do próprio cenário de impasses e dificuldades no qual os estudantes indígenas encontram-se submetidos ao ingressarem na universidade. Reconhecendo a importância das ações afirmativas da Ufopa, as autoras apontam para a necessidade de que as conexões entre as universidades e os grupos atendidos por meio dessas ações sejam cada vez mais estreitadas para que esses grupos, de fato, possam se firmar do ponto de vista étnico e político.

O texto de abertura da parte II da obra (Experiências de Ensino de História) é: "A história regional e o Baixo Amazonas: reflexões sobre ensino e pesquisa”, de Vanice Siqueira de Melo. Nele, a autora relata sua experiência docente na organização e implementação da disciplina de História da Amazônia I, para os alunos do curso de graduação de História da Ufopa. A preocupação com a inclusão das discussões historiográficas sobre a região do Baixo Amazonas revela a baixa produção acadêmica, de dimensão histórica, em torno desse recorte regional. Recorrendo a algumas fontes do Arquivo Público do Estado do Pará, a autora traça um panorama da historiografia da Amazônia colonial. A constituição do espaço geográfico como elemento central de sua trajetória de pesquisa ocupa a centralidade de suas reflexões.

Em “O 'lugar' da história da África e das africanidades no curso de história da Universidade Federal do Oeste do Pará (Ufopa): entrecruzamentos e sensibilidades”, segundo texto da seção, o autor Gustavo Pinto de Sousa parte da seguinte indagação: Qual o lugar da história da África e das africanidades no curso de História da Ufopa? A preocupação com essa questão permeia toda a discussão do autor que aponta a necessidade de se pensar o ensino da história da África e das africanidades muito além do cumprimento de dispositivos legais e acadêmicos, mas, sobretudo, a partir de uma perspectiva não hierarquizada do conhecimento histórico. Nesse sentido, o autor analisa a forma de estruturação do Projeto Político Pedagógico do curso de licenciatura em História da Ufopa, e das ementas das disciplinas que compõem o curso, a partir de reflexões conduzidas pelo exercício constante da sensibilidade, da identidade e da alteridade na conexão entre os mais diversos saberes.

"Passos e descompassos entre o saber acadêmico e o saber escolar: as experiências do programa institucional de bolsa de iniciação à docência de História (PIBID-HISTÓRIA) da 
Universidade Federal do Oeste do Pará (Ufopa)" é o terceiro texto da parte II da obra. Seus autores, Diego Marinho de Gois e Lademe Correia de Sousa, partindo da consideração do protagonismo da escola no processo de ensino-aprendizagem e no reconhecimento de uma cultura que lhe é própria, procuram, em suas análises, redimensionar o papel da universidade em relação ao saber escolar. Nesse sentido, os autores enfatizam a importância da história local como meio de construção do conhecimento histórico pelos alunos na escola básica, a partir do relato de um projeto do PIBID²- História da Ufopa, desenvolvido em três escolas da rede pública de ensino da região de Santarém. Para além do saber acadêmico como referência na constituição do saber escolar, os autores problematizam a importância de se levar em conta as práticas e demandas da cultura escolar na constituição de um ensino mais significativo.

Em "Reflexões sobre ensino e pesquisa em história indígena no Pará e em Minas Gerais", quarto texto da seção, Gefferson Ramos Rodrigues traz um relato de sua trajetória de pesquisa a respeito da presença indígena em vários movimentos contestatórios no Brasil colonial, a fim de reafirmar a importância de uma história interdisciplinar (etno-história) nas abordagens realizadas em torno da questão indígena. Contrastando o sertão amazônico e o sertão do São Francisco, em relação à ocupação indígena nesses territórios, o autor apresenta algumas reflexões que o fizeram repensar sua própria prática docente e suas atividades de pesquisa, diante de uma realidade bastante diferente em relação às suas experiências anteriores, como a de trabalhar com alunos originários das mais variadas culturas indígenas da região.

Fechando a parte II, a obra apresenta o texto intitulado: "A história econômica da Amazônia oitocentista em sala de aula: um proveitoso percurso de análise e ensino", de Luiz Carlos Laurindo Junior. Nele, o autor tece considerações sobre as potencialidades e os limites das principais produções historiográficas que investigam a economia da Amazônia no século XIX. Propondo um novo percurso de análise que leve em conta a diversidade e o dinamismo que caracterizaram a economia da região e, sobretudo, as especificidades da inserção dessa região dentro da lógica do sistema capitalista mundial, o autor redimensiona o papel que a Amazônia exerceu no cenário econômico oitocentista.

O texto "A pergunta sobre o "nós", de Augusto B. de Carvalho Dias Leite e Erick Araujo abre a terceira e última seção da obra. Nele, os autores partem da seguinte indagação: como criar as condições em sala de aula para que alunos, professores e os sujeitos que abstratamente nos relacionamos possam se dizer "nós"? Essa indagação perpassa toda a discussão proposta pelos autores que apontam a necessidade de fugirmos do isolamento e da

\footnotetext{
${ }^{2}$ Programa Institucional de Bolsa de Iniciação à Docência.
} 
homogeneização em busca de nossa conexão com o outro, seja o outro do presente, ou do passado, do aqui ou do acolá. As experiências relatadas pelos autores, ao longo do texto, colocam em evidência a condição primeira da atividade do historiador: o encontro com o outro.

O que uma peça grega antiga como Oresteia de Ésquilo teria a nos dizer sobre a ideia de justiça no mundo atual? Que similitudes as redes de intriga do presente guardam das histórias encenadas no teatro grego antigo? Em "Piranhas que bebem sangue: tragédia grega e permanência em nossos sertões", a autora e organizadora da obra, Lorena Lopes da Costa, encerra a terceira e última parte da coletânea. No texto, a autora faz um relato dos desafios e da experiência em sala de aula ao conectar conceitos como vingança e justiça no mundo grego e, por extensão, conectar a própria obra Oresteia (oferecida como documento de análise numa disciplina optativa por ela ministrada), tão distante no tempo e no espaço, à realidade vivida por seus alunos, sujeitos do sertão amazônico, ressignificando a ideia de permanência na história.

$\mathrm{O}$ aspecto singular de todas as reflexões contidas na obra assinala a importância e a emergência da multiculturalidade e das particularidades regionais na formação dos professores de História. A diversidade cultural, linguística e étnica que caracteriza o corpo discente da Ufopa trouxe como desafio aos seus professores um novo olhar sobre a experiência docente, suas práticas e o alcance de suas ações, seus objetos de pesquisa e sobre as questões e problemas específicos da região e de seus habitantes. A ampliação dessas reflexões para além dos espaços regionais já há muito consagrados pela historiografia, sobretudo por uma historiografia produzida fora dos grandes eixos urbanos, denota um movimento significativo de muitos desses professores/pesquisadores em se romper com a ideia de identidades únicas, tão ao gosto de alguns grupos políticos atuantes no cenário nacional, em direção a uma concepção múltipla das identidades, entendidas como processos marcados por diferenças, que se constituem cultural e historicamente.

Tais reflexões retiram os sujeitos do esquecimento: os alunos, pelo reconhecimento de suas origens, seus saberes e suas histórias, e os próprios docentes, por serem autores de produções acadêmicas tão relevantes, sinalizando em suas produções a diversidade e a complexidade das culturas do sertão amazônico, tão pouco conhecidas e reconhecidas pelos tradicionais centros de pesquisa do país.

Cabe aqui uma observação em relação ao prefácio da obra, escrito por Elizabeth dos Santos Braga, professora e pesquisadora da Faculdade de Educação/USP. Nele, a autora ressalta a dimensão política que a obra adquire, sobretudo no contexto atual em que as falsas palavras (numa referência a Paulo Freire) restringem cada vez mais o diálogo com o mundo. Diante de um processo cada vez mais contundente de cerceamento de direitos historicamente 
conquistados, em decorrência da atuação de grupos políticos ultraconservadores, o texto do prefácio nos lembra que as universidades públicas se encontram sob ataque. As razões das constantes investidas contra essas instituições encontram como justificativa a associação das universidades a lugares contaminados por um "viés ideológico de esquerda", invertendo assim a própria lógica de existência dessas instituições, qual seja a de justamente fomentar uma cultura acadêmica pautada pelos princípios da pluralidade de ideias, da liberdade de expressão e da diversidade cultural. Esses ataques vêm provocando um forte impacto nas atividades de ensino e pesquisa, sobretudo, nos cursos da área de humanidades, os quais, na visão dos referidos grupos, não produziriam um "retorno imediato" à sociedade, num claro desprezo em relação à relevância e à diversidade de conhecimento produzido dentro dessas instituições. Nesse sentido, o texto do prefácio levanta a importância da obra em pronunciar as experiências como forma de (re)conhecimento dos relatos ali presentes, mas também como forma de luta contra o esquecimento e contra o silenciamento e, no limite, como forma de luta por uma existência mais humana.

A obra, portanto, coloca em foco a potência de práticas docentes na área de História sertão afora. Sua força está em mostrar em detalhes o trabalho dos professores: seus limites, conquistas, dores e desafios, reafirmando a máxima freiriana de que, definitivamente, não existe ensinar sem aprender (FREIRE, 2001).

As experiências relatadas asseveram o reconhecimento dos vários modos de ser e de estar no mundo, o (re)conhecimento de um "outro", que existe em sua concretude ou abstratamente. Esse "outro" nos coloca diante de nós mesmos, nos convida a olhar além, a olhar junto; mais do que a diferença, o que encontramos é um lado de nós mesmos, até então desconhecido. Para além dos limites geográficos, poderíamos pensar o outro como tudo o que nos circunda, cujo estranhamento alicerça as bases do reconhecer-se, seja esse outro aquele do recôndito sertão amazônico, seja o outro ali da esquina.

É certo que ninguém escapa da história; mais certo ainda é que a história é um constante processo de refazer-se, e cada nova experiência partilhada, tais como as relatadas na obra, aponta em direção a um futuro em aberto, na medida em que as experiências carregam consigo o potencial de iluminar o entendimento do vivido e inspirar a construção do novo. As experiências dos outros quando olhadas num espelho negativo, conforme sugere Calvino, refletem a nós mesmos, mas também aquilo que ainda não havíamos visto, aquilo que permanece oculto, ainda futuro e que está por ser construído. É por isso que cada experiência relatada na obra nos enche de esperança de que toda resistência não será em vão. 


\section{REFERÊNCIAS}

CALVINO, Ítalo. As Cidades Invisíveis. Rio de Janeiro: Biblioteca Folha de S. Paulo, 2003.

CERTEAU, Michel de. A escrita da história. 2. ed. Rio de Janeiro: Forense Universitária, 2002.

FREIRE, Paulo. Carta de Paulo Freire aos professores, Revista de Estudos Avançados, 15 (42), ago. de 2001, Disponível em: https://doi.org/10.1590/S0103-40142001000200013. Acesso em: 05/07/2021.

Recebido em: 20 de dezembro de 2021 Aceito em: 20 de dezembro de 2021 